\title{
Editorial: Expanding Opportunities for Research
}

\section{Deb Carver, Philip H. Knight Dean of Librarians}

I've been fortunate to attend several excellent universities as an undergraduate and as a graduate student. As an undergraduate, I had plenty of opportunities to write the classic "term paper." The process taught me a lot about organizing my thoughts, finding relevant information, and reaching conclusions that were backed up by the evidence. But I do not remember feeling challenged. I was systematically collecting the facts and opinions from others, and putting them into my own words. Needless to say, my papers were saturated with citations and footnotes. But, I wasn't adding anything to the scholarship of my discipline.

I have noticed one profound and very positive change since my undergraduate years. Undergraduate research has become a core focus across the disciplines. This change has occurred at many of the research universities across the country--including the University of Oregon. In the sciences, that research often occurs in the lab. Increasingly, scientific investigation takes place online using high performance computing capabilities. In the social sciences, some of that research takes place in the field. In the humanities, undergraduate research often happens in the library. Not with the secondary sources that I used as an undergraduate student, but with primary sources such as manuscripts, archives, rare books and government documents.

When I was a student, these 'special collections' were sometimes off limits to undergraduates. The manuscript reading rooms were filled with only the most seasoned scholars, breathing rarified air, carefully reviewing a file folder with white gloves. Not the most welcoming place on campus for the typical student. Thankfully, most research libraries now actively encourage undergraduates to use the collections and discover the intellectual challenges associated with original research. New theories, interpretations and discoveries can happen at any time during one's academic career. The thrill of saying something that no one has said before can be transformative. I do not know this for certain, but I suspect that those students who have the opportunity--and the support--to engage in original research, go on to become active lifelong learners.

Today, the Special Collections reading room at the University of Oregon is one of the busiest places in the library. Students take a break from the computer and the smart phone to engage with the past. They ask lots of questions. They're curious about their cultural history. They see a rich and diverse resource ready for exploration. They begin to see themselves as scholars. (White gloves are no longer required). This is what a research university is all about. 